When "happy" means "sad"

\title{
When "happy" means "sad": Neuropsychological evidence for the right prefrontal cortex contribution to executive semantic processing
}

\author{
Dana Samson, Catherine Connolly \& Glyn W. Humphreys
}

University of Birmingham

Running head: When "happy" means "sad"

Short title: Right prefrontal cortex and semantics

Published in Neuropsychologia, 45(5), 896-904

Address for correspondence:

Dana SAMSON

Behavioural Brain Sciences Centre

School of Psychology - Hills Building

University of Birmingham

Edgbaston

Birmingham, B15 2TT, U.K.

Tel: ++44 (0) 1214143661

Fax: ++44 (0) 1214144897

E-mail: d.samson@bham.ac.uk 
When "happy" means "sad" 
When "happy" means "sad"

\begin{abstract}
The contribution of the left inferior prefrontal cortex in semantic processing has been widely investigated in the last decade. Converging evidence from functional imaging studies shows that this region is involved in the "executive" or "controlled" aspects of semantic processing. In this study, we report a single case study of a patient, PW, with damage to the right prefrontal and temporal cortices following stroke. PW showed a problem in executive control of semantic processing, where he could not easily override automatic but irrelevant semantic processing. This case thus shows the necessary role of the right inferior prefrontal cortex in executive semantic processing. Compared to tasks previously used in the literature, our tasks placed higher demands on executive semantic processing. We suggest that the right inferior prefrontal cortex is recruited when the demands on executive semantic processing are particularly high.
\end{abstract}

Keywords: prefrontal cortex; right hemisphere; semantic processing; executive function; selection 


\section{Introduction}

There is now an accumulating body of evidence showing that semantic processing is not only sustained by the temporal lobes, but also by prefrontal cortices, especially the left inferior region (see Fletcher \& Henson, 2001, for a review). More particularly, the evidence suggests that the left inferior prefrontal cortex (LIPC) is involved in "executive" or "controlled" semantic processing. Functional imaging studies have shown, for example, that the activity in the LIPC decreases when a word is semantically processed for the second time (repetition priming; Demb et al., 1995; Wagner, Koutstaal, Maril, Schacter, \& Buckner, 2000). On the other hand, activity in the LIPC increases in different experimental conditions. For example, Wagner and colleagues (Wagner, Pare-Blagoev, Clark, \& Poldrack, 2001) asked their participants to judge which word within a set of choice words (e.g. "flame" and "bald") was closest in meaning to a cue (e.g. "candle"). They found increased activity in the LIPC as the number of words in the choice set increased (from 2 to 4 ) and as the strength of association between the cue and the target decreased (a target weakly associated to the cue requiring more semantic processing; for similar findings see Bunge, Wendelken, Badre, \& Wagner, 2005). Increased LIPC activity has also been found when hard semantic judgements are required (category membership judgement for nonprototypical exemplars, e.g. does "earl" belong to the "royalty" category?) compared to easier semantic judgements (category membership for prototypical exemplars, e.g. does "king" belong to the "royalty" category?; Roskies, Fiez, Balota, Raichle, \& Petersen, 2001). Thompson-Schill and colleagues also found increased LIPC activity when the semantic task required selecting a task-relevant semantic dimension 
When "happy" means "sad"

(Thompson-Schill, D'Esposito, Aguirre, \& Farah, 1997; Thompson-Schill, D'Esposito, \& Kan, 1999). For example, they found greater LIPC activity when the semantic judgement was based on a specific semantic feature (e.g. amongst "tongue" and "bone" which has the same colour as "tooth") than when it was based on global semantic similarity (amongst "tick", "well", "shoe", "school" which is most similar to "flea"; Thompson-Schill et al., 1997). There was also increased LIPC activity when an action had to be generated from an object that could be associated with many different actions (e.g. "wheel”) compared to an object that was more uniquely associated to a specific action (e.g. "scissors"; Thompson-Schill et al., 1997); LIPC activity further increased when participants had to generate a word based one specific feature related to the cue (e.g. an action related to "dollar") and then later generate a word based on a different feature related to the same cue (e.g. a colour related to “dollar”; Thompson-Schill et al., 1999). More recently, increased LIPC activity has also been found in a picture naming task, when the item (e.g. the picture of a shark) was preceded by a highly associated distractor (e.g. participant had previously named a "whale" from a verbal description; Moss et al., 2005) or in lexical decision, when the target word was preceded by a semantically incongruent as compared to a semantically congruent context (e.g. "head" preceded by "There was no hair on his..."; Cardillo, Aydelott, Matthews, \& Devlin, 2004).

This evidence for the LIPC involvement in executive semantic processing comes mainly from functional imaging studies, though there is also converging evidence indicating the necessary role of LIPC in executive semantic processing. For example, semantic processing can be affected when transcranial magnetic stimulation (TMS) interferes with LIPC activation or when LIPC is damaged following acquired brain 
When "happy" means "sad"

lesions. TMS applied to the LIPC can reduce repetition priming in a semantic task (Thiel et al., 2005) and accuracy in semantic categorisation (Devlin, Matthews, \& Rushworth, 2003). Moreover, patients with lesions to LIPC show greater difficulties in selecting the context-appropriate meaning of ambiguous words (Metzler, 2001) or the relevant action to an object, especially when several possible actions can be associated with that object (Thompson-Schill et al., 1998).

Despite the general agreement on the executive or controlled nature of the semantic processing associated with the LIPC, several issues remain hotly debated. For example, it is controversial as to whether the executive role of the LIPC is more linked to semantic retrieval or semantic selection (Badre, Poldrack, Pare-Blagoev, Insler, \& Wagner, 2005; Moss et al., 2005; Thompson-Schill et al., 1999; Wagner et al., 2001). Other issues concern the functional specialisation within the LIPC (e.g., Badre et al., 2005; Bunge et al., 2005) and whether the executive role of the LIPC is restricted to semantic processing (e.g., Gold, Balota, Kirchhoff, \& Buckner, 2005; Zhang, Feng, Fox, Gao, \& Tan, 2004).

Studies investigating executive semantic processing have focused on the left side of the inferior prefrontal cortex. In almost all cases, the right IPC side was either not part of the region of interest, not discussed, or simply not observed. One exception is the study by Wagner and colleagues (Wagner et al., 2001) who asked their participants to judge which word among a set of choices was most related to a cue. The authors found bilateral activation in the IPC; both hemispheres were sensitive to the strength of association between the target and the cue (with increased activation when the association was weak), but unlike the left side activation, the right side activation was 
When "happy" means "sad"

not modulated by the number of choice words. The authors speculated that the right inferior prefrontal cortex might be only recruited when demands on executive semantic processing are particularly high. Consistent with this idea is the finding that during an auditory semantic similarity judgment task, left prefrontal activation is observed when the stimuli are presented in a clear speech condition but right prefrontal activation is observed when the stimuli are presented in an acoustically degraded form, presumably because the controlled processes increase in that latter condition (Sharp, Scott, \& Wise, 2004).

In this study we report the case of a patient who presented with a deficit in executive semantic processing, but who, contrary to prior cases, suffered damage to the right inferior frontal and superior temporal cortices. The deficit became apparent under conditions where competition for selection between semantic representations was maximised. The data suggest the necessary role of the right hemisphere in selecting semantic representations under high levels of competition.

\section{Case report}

PW was a retired florist who was 72 years old at the time of testing. Four years prior to the testing, he suffered a right hemisphere stroke which affected the right middle and inferior frontal gyri as well as the right superior temporal gyrus (see Figure 1). As a result of his stroke, PW showed a left upper limb hemiplegia and as most obvious cognitive impairment, executive function deficits. PW was strongly right-handed and 
When "happy" means "sad"

scored 10/10 for right hand responses on everyday tests, measured using the Edinburgh Handedness Inventory.

Insert Figure 1 about here

On formal testing, PW showed good orientation in time and space as well as relatively spared verbal and visual long term memory. On the Elevator Counting test (Robertson, Ward, Ridgeway, \& Nimmo-Smith, 1994), PW scored 6/7 showing slight difficulties in sustained attention. On part B of the Trail Making Test (Reitan, 1958), PW's performance was spared (between the percentile 50 and 75). Nevertheless, a clear impairment in executive function was apparent in the Brixton Spatial Anticipation test where PW made 35 errors (Burgess \& Shallice, 1997) and the Hayling Test (Burgess et al., 1997) where PW had an overall scaled score of 1, with performance on both tasks being classified as "impaired". In a task designed to test response inhibition (i.e. when you see one finger raised say "two"; when you see two fingers raised say “one”), PW's score was significantly below the normal range (-6.72 $\mathrm{SD})$.

PW's language abilities were assessed on a range of formal tests. His score on the Category-Specific Names Test (McKenna, 1997), a difficult picture naming test, was spared: he named 17/30 correct for non-praxic objects ( 0.97 SD below the controls' mean score), 18/30 for praxic objects (1.47 SD below the controls' mean score), 20/30 for animals (0.55 SD below the controls' mean score) and 19/30 for fruit and vegetables (0.34 SD below the controls' mean score). PW's scores were slightly impaired on an oral and written synonym judgment task for concrete and abstract 
When "happy" means "sad"

words (scoring $76 \%$ and $75 \%$ correct respectively) as well as on an oral and written sentence/picture matching task (PW scored 73\% and 70\% correct respectively, PALPA tests 55-56, Kay, Lesser, \& Coltheart, 1992). Quite strikingly, in these latter tasks, most of PW's errors consisted in choosing the opposite meaning of the target (e.g. for the sentence "the girl's selling the cat", PW choose the picture of a girl buying the cat; for the sentence "This girl's got less dogs", PW choose the picture of the girl with most dogs). In an auditory comprehension of locative relations (PALPA test 58, Kay et al., 1992), PW scored 54\% overall correct and all but one error consisted in selecting the opposite meaning of the target (e.g. "above" instead of "below" or "in front" instead of "behind").

Interestingly, "opposite meaning” errors were the only language problems apparent in PW's spontaneous speech production and comprehension. PW would complain, for example, that he couldn't play his favourite card game anymore, because he confused the words "higher" and "lower". In conversations with us, he would produce sentences like "flu jabs have been recommended for people under the age of 65 ". When asked to resolve simple arithmetic, he would perform subtractions instead of additions (e.g. $8+2=6$ ) and, when asked what days comes after a certain target day of the week (e.g. Wednesday), he would give the day that comes before (e.g. Tuesday). Note that these errors were observed although PW was perfectly able to recite the sequence of the days of the week in the correct order.

PW's “opposite meaning” errors were the subject of this study, where we investigated the extent to which the occurrence of these semantic errors depended on the executive demands placed on semantic processing. 
When "happy" means "sad"

\section{Experiment 1: synonym/antonym distractors}

The first experiment consisted of a semantic judgement task in which PW was asked to choose from amongst three words the one which was related to the cue, according to a pre-defined semantic dimension. For example, the participant would be asked to choose the word that is closest in meaning to the cue "happy" from the alternatives "cheerful", "sad" and "conscious". If we assume that processing the cue would automatically activate words that are related in meaning in semantic memory, then the executive demands of semantic processing can be varied by manipulating whether this automatic semantic activation needed to be controlled/overruled to achieve the correct, task-relevant matching. Accordingly, we varied the strength of association between the cue and the distractor or target (this was measured through word association norms and was taken as an indicator of the extent to which one word automatically activates another word at a lexical/semantic processing level, e.g. Wagner et al., 2001). In the "strongly associated distractor" condition, the distractor was strongly associated to the cue whereas the target was weakly associated to the cue. In our above example, the word "sad" is more strongly associated to "happy" than the word "cheerful". The cue (here "happy") would thus automatically activate the distractor (e.g. "sad") more than (and/or prior to) the target (e.g. "cheerful"). It follows that selecting the target over the distractor would require any competition from the distractor to be resolved (e.g., to suppress the distractor). Thus, in this case, the demands on executive processes should be high. In contrast, in the "weakly associated distractor" condition, the distractor was weakly associated to the cue while the target was strongly associated. For example, the cue word "neat" would be 
When "happy" means "sad"

presented with the alternatives "tidy", "messy" and "lucky". In this example, "tidy" is more strongly associated than "messy" to the cue "neat". Here, the cue (e.g. "neat") would automatically activate the target (e.g. "tidy") more than (and/or prior to) the distractor ("messy"). In this circumstance, selecting the target over the distractor should be less demanding in terms of executive control.

\subsection{Method}

PW was presented with a series of 144 trials. Each trial consisted of a cue word and 3 choice words. All the words were presented on A5 cards and were written in capital letters using black ink for the cue on the top of the card and blue ink for the three choice words presented in one row beneath the cue. The words were either nouns, verbs, adjectives, adverbs or prepositions but, on a given trial, the cue and the three choice words always shared the same grammatical class. Amongst the three choice responses, one was a synonym of the cue, one was an antonym and one was an unrelated word. The order of each type of choice word was balanced across trials. Synonyms and antonyms were selected via the use of an on-line thesaurus (http://thesaurus.reference.com). For half of the trials $(n=72)$, the synonym was highly associated to the cue whereas the antonym was weakly associated to the cue. So, for example, the cue word "neat" would be presented with the following three choices: "tidy" for the synonym, "messy" for the antonym and "lucky" for the unrelated word. For the other half of the trials $(n=72)$, the antonym was highly associated to the cue but the synonym was weakly associated. For example, the cue would be "happy" and the three choice words would be "cheerful" for the synonym, "sad" for the antonym and "conscious" for the unrelated word. Associative strength norms were taken from the Edinburgh Associative Thesaurus (Kiss, Armstrong, Milroy, \& Piper, 1973; 
When "happy" means "sad"

http://www.eat.rl.ac.uk). All sets of words were presented twice across two testing sessions; in one condition, the participant was asked to choose the word closest in meaning to the cue (synonym condition) and in another condition, the participant was asked to choose the word that means the opposite to the cue (antonym condition). The order of presentation of the conditions was counterbalanced, so that half of the trials (set 1) were first presented in the synonym condition and the other half (set 2) in the antonym condition. In the synonym condition, the executive demands are high when the antonym is highly associated to the cue (the strongly associated distractor condition) while the executive demands are low when the antonym is weakly associated to the cue (the weakly associated distractor condition). Similarly, in the antonym condition, the executive demands are high when the synonym is highly associated to the cue (the strongly associated distractor condition), but executive demands are low when the synonym is weakly associated to the cue (the weakly associated distractor condition). Figure 2 summarises the design of Experiment 1 and the materials are given in the Appendix.

The task was presented to PW as well as to two control participants (aged 56 and 57 at the time of testing) matched for educational background.

Insert Figure 2 about here

\subsection{Results and Discussion}

The controls performed the task easily and scored above $94 \%$ correct in all conditions. PW's performance is displayed in Figure 3. In the synonym condition, PW's score was significantly better in the weakly associated distractor condition $(56 / 72,78 \%$ 
When "happy" means "sad"

correct) than in the strongly associated distractor condition $(41 / 72,57 \%$ correct; $\mathrm{Z}=2.67, \mathrm{p}<0.01$ ). In the antonym condition, the same profile was observed (weakly associated distractor: 39/72, 54\% correct; strongly associated distractor: 18/72, $25 \%$ correct; $\mathrm{Z}=3.58, \mathrm{p}<0.001)$. Moreover, overall the score was better in the synonym condition $(97 / 144,67 \%$ correct) than in the antonym condition $(57 / 144,40 \%$ correct; $\mathrm{Z}=4.73, \mathrm{p}<0.001)$. Note that PW's errors never consisted in choosing the unrelated word; instead he chose the antonym instead of the synonym and vice versa.

Given the norms available, it was impossible to perfectly control for word frequency in creating the stimuli. Thus, in order to assess the contribution of word frequency to PW's score, we performed a logistic regression analysis with PW's score as the dependent variable and with the following predictor variables: cue frequency, target frequency (synonym target in the analysis of the synonym condition, and antonym target in the antonym condition), distractor frequency (antonym distractor in the analysis of the synonym condition, and synonym distractor in the analysis of the antonym distractor), task-relevant semantic dimension (synonym versus antonym) and strength of association between the cue and distractor (strong versus weak). The full model was reliable $\left(\chi^{2}(5)=47.39, \mathrm{p}<0.001\right)$ and confirmed the significant effects of the task-relevant semantic dimension (Wald $(1)=24.62, \mathrm{p}<0.001)$ and the strength of association between the cue and distractor (Wald $(1)=17.44, \mathrm{p}<0.001)$ once the cue, target and distractor frequency were partialled out (and these three frequency effects were not significant, Wald $<1$ ).

Overall, the results indicate that PW was more likely to choose the word most strongly associated to the cue, irrespective of whether that word fitted the instruction 
When "happy" means "sad"

to select the synonym or the antonym to the cue. Thus, PW's could not easily override automatic semantic activation (occurring through word association) when this was not relevant to the task - a profile consistent with difficulties in executive semantic processing. Over and above the effect of strength of association, PW was also more inclined to select the synonym rather than the antonym to the cue, irrespective of whether the instruction was to find the synonym or the antonym. One explanation for this latter finding is that "matching" responses (same meaning) are more automatic/less demanding than "mismatching" responses (opposite/not the same meaning). Alternatively, it could be that a word activates more automatically its synonym(s) than its antonym(s) (possibly because of greater semantic similarity between synonyms than antonyms). Either way, PW could not focus on the taskrelevant semantic dimension if it was not the one activated automatically.

Insert Figure 3 about here

\section{Experiment 2: semantic associate (non-antonymous) distractor}

In the second experiment, the aim was to investigate if PW's difficulty in resisting interference from strongly associated distractors was confined to words that are synonyms/antonyms or if it extended to words having other semantic relations. PW was thus presented with a synonym judgement task, in which the distractor was a semantically associated, but non-antonymous, word.

\subsection{Method}


When "happy" means "sad"

Eighty-four trials were created using the same criteria as in Experiment 1. The sole difference was that the antonym distractor was replaced by a more distant semantic associate (non-antonym and non-coordinate) word (e.g. for the cue "piece", the choice responses would be "slice" for the synonym, "cake" for the semantic associate and "resident" for the unrelated word). On half of the trials $(n=44)$, the synonym was highly associated to the cue while the semantic associate was not (weakly associated distractor condition). For the other half of the trials $(n=44)$, the semantic associate was highly associated to the cue while the synonym was not (strongly associated distractor condition). For all trials, PW was asked to choose the word closest in meaning to the cue (synonym condition only). The materials are given in the Appendix. Experiment 2 was also presented to the two control participants used in Experiment 1.

\subsection{Results and Discussion}

The controls again performed the task easily and scored above $93 \%$ correct in all conditions. PW's performance was better in the weakly associated distractor condition $(32 / 42,76 \%$ correct $)$ than the strongly associated distractor condition $(23 / 42,55 \%$; $\mathrm{Z}=2.07, \mathrm{p}<0.05$ ). The level of accuracy was strikingly similar to the level of accuracy observed in the synonym condition of Experiment 1 (see Figure 3). All but two errors consisted in choosing the semantic associate instead of the synonym.

In order to investigate the effect of word frequency, we conducted a logistic regression analysis with PW's score as the independent variable and with the following predictor variables: cue frequency, target frequency, distractor frequency 
When "happy" means "sad"

and strength of association between the cue and the distractor (strong versus weak) ${ }^{1}$. The full model was marginally significant $\left(\chi^{2}(4)=9.32, \mathrm{p}=0.05\right)$ but showed a significant effect of competition level (Wald $(1)=5.81, \mathrm{p}<0.05)$ once the cue, target and distractor frequency were partialled out (these three factors were not significant; cue frequency: Wald $(1)=2.58, p=0.11$; target frequency: Wald $(1)=2.73, p=0.10$; distractor frequency: Wald $(1)<1)$. We conducted an additional analysis, pooling together the data of the synonym conditions in Experiments 1 and 2, adding the type of distractor (antonym versus associate) as a predictive variable to the variables entered in the previous analysis. The full model was significant $\left(\chi^{2}(5)=17.44\right.$, $\mathrm{p}<0.01)$ and showed as sole significant effect the strength of association between the cue and the distractor once all the other factors were partialled out (Wald $(1)=10.87$, $\mathrm{p}<0.01)$. So it was not the interference created by antonyms per se that affected PW's performance, rather, it was the interference created by strongly associated but irrelevant words.

\section{General Discussion}

PW was presented with semantic judgement tasks in which he was asked to choose among a set of words the one which was related to a cue according to a predefined semantic dimension. PW's performance was strongly influenced by the executive semantic demands of the task. He made errors particularly when the distractor word was more strongly associated to the cue than the target (e.g. choosing "sad" instead of "cheerful" as synonym of "happy") and he made more errors when the task demanded

\footnotetext{
${ }^{1}$ For this analysis we excluded the two items for which PW's errors consisted in choosing the unrelated word.
} 
When "happy" means "sad"

that he match words opposite in meaning (e.g. PW was able to decide that "offer" and not "take" means the same as "give" but not that "take" and not "offer" means the opposite to "give"). Such errors suggest that PW's responses tended to be based on semantic activation that arose automatically in word processing (through word association and possibly semantic similarity) rather than executive semantic processing, where automatic semantic processing may be over-ruled.

As noted in the Introduction, executive semantic processing has mainly been associated with the left inferior prefrontal cortex (e.g., Badre et al., 2005; Cardillo et al., 2004; Demb et al., 1995; Devlin et al., 2003; Metzler, 2001; Moss et al., 2005; Thompson-Schill et al., 1997; Thompson-Schill et al., 1998; Thompson-Schill et al., 1999; Wagner et al., 2000; Wagner et al., 2001; Zhang et al., 2004). Yet, in the case of PW, impaired executive semantic processing was observed following a lesion affecting the right inferior prefrontal and superior temporal cortices. At least four explanations can be offered for this neuroanatomical discrepancy. One possibility is that PW has unusual lateralisation of language functions, with some language functions localised on the right side. However, this seems very unlikely. PW was strongly right handed and he had no language deficits other than those noted here. A second possibility is that PW's pattern of impairment resulted from his right temporal rather than right prefrontal lesion. The anterior part of the temporal lobes has been mainly associated with a function of "semantic integration" when higher order semantic relations need to be processed, such as in the case of comprehension of discourse, metaphors or jokes. Semantic integration would be achieved by the cooperation of both hemispheres but with the right anterior temporal lobe holding the critical role of sustaining coarse semantic processing (e.g. the processing of weaker or 
When "happy" means "sad"

more distant semantic relations allowing for the recognition of broader or novel meaning) while the left anterior temporal lobe would sustain more refined semantic processing (for a review, see Jung-Beeman, 2005). However, our semantic judgement tasks were not very demanding in terms of semantic integration since our tasks required processing the meaning of single words rather than sentences and included words that were largely unambiguous in meaning. Moreover, even when PW had to match weakly associated words (measured through word association norms), the words were still synonyms or antonyms, and not semantically distant words. We do not exclude the possibility that PW suffered difficulties in semantic integration or coarse semantic processing in addition to the deficits highlighted in this paper. However, we would like to argue that PW's difficulties in our semantic judgement tasks were more likely due to difficulties in semantic selection rather than semantic integration. This still leaves the possibility open that the right anterior temporal lobe is also involved in semantic selection. The third possibility is that lesions to the right hemisphere (most likely the inferior prefrontal cortex) affect the functional integrity of the LIPC. Such an explanation would be compatible with the functional imaging findings and reinforce the hypothesis that executive semantic processing is actually sustained by the LIPC. The fourth possibility is that the right inferior prefrontal cortex might, by itself, play a crucial functional role in executive semantic processing. The question is then, why is this role not more apparent in functional imaging studies? One answer can be found when comparing the executive demands in our task with the executive demands of tasks usually used in the literature.

In previous published work, the higher executive demands introduced in the studies involved increasing the number of words being processed simultaneously (e.g., 
When "happy" means "sad"

Wagner et al., 2001), weakening the automatic semantic activation of the target (e.g., Bunge et al., 2005; Thompson-Schill et al., 1997; Thompson-Schill et al., 1998;

Thompson-Schill et al., 1999; Wagner et al., 2001), focusing on a semantic dimension other than global semantic similarity (e.g., Thompson-Schill et al., 1997), and enhancing activation of semantic competitors (e.g., Cardillo et al., 2004; Moss et al., 2005). We propose that the executive demands on semantic processing in our tasks were even higher than in the previous studies. The main executive demand that we manipulated is the enhancement of activation from the competitors (through the use of distractors that were more highly associated to the cue than the targets). In previous studies, competitors were either not presented simultaneously with the target (they were presented several trials earlier; Moss et al., 2005) or were not explicitly present (the competitors were primed by an incomplete sentence; Cardillo et al., 2004). In our tasks, the competitors were presented explicitly and, in addition, were highly related to the cue through word association, arguably creating particularly strong competition.

Thus, our findings provide direct evidence that the right hemisphere (inferior prefrontal and superior temporal cortices) is necessary for executive semantic processing; however, which part of the right hemisphere and exactly which role will need to be addressed by future studies. We hypothesise that the right inferior prefrontal cortex is necessary when executive demands on language processing are high, and that this region plays an important functional role by intervening when there is high executive demand (as also suggested by Sharp et al., 2004; Wagner et al., 2001). If this latter suggestion is correct, we would expect to find in healthy adult participants increased right inferior prefrontal activation as the demands in executive semantic processing increase in a task. 
When "happy" means "sad"

\section{Acknowledgments}

We are very grateful to PW for his cheerful participation in this study. This study was supported by grants from the Medical Research Council and the Stroke Association (U.K.). 
When "happy" means "sad"

\section{Appendix}

Test 1

Synonym highly associated to the cue (set 1)

CUE

SYNONYM

ANTONYM

UNRELATED

abandon

leave

keep

ask

absent

away

present

great

achievement

success

failure

condition

actual

real

imaginary

fond

allow

permit

refuse

spread

almost

nearly

exactly

ahead

artificial

false

natural

lean

clever

intelligent

stupid

pure

clothe

dress

strip

drift

complain

moan

praise

leap

confess

admit

deny

reach

connect

join

divide

flush

construct

build

demolish

throw

costly

dear

cheap

silent

create

make

destroy

scream

discover

find

miss

work

enormous

huge

tiny

bitter

exhausted

tired

refreshed

funny

extremely

very

moderately

already

fantasy

dream

reality

ability 
When "happy" means "sad"

\begin{tabular}{|c|c|c|c|}
\hline fascinating & interesting & boring & tribal \\
\hline ferocious & fierce & gentle & wooden \\
\hline fluid & liquid & solid & blond \\
\hline frighten & scare & reassure & choose \\
\hline injure & hurt & aid & repeat \\
\hline joy & happiness & sorrow & arrangement \\
\hline loathe & hate & love & notice \\
\hline neat & tidy & messy & lucky \\
\hline occupied & busy & vacant & general \\
\hline prevent & stop & allow & hear \\
\hline release & free & hold & act \\
\hline retain & keep & lose & play \\
\hline reveal & show & conceal & depend \\
\hline sick & ill & healthy & steady \\
\hline simple & easy & complex & rotten \\
\hline unite & join & separate & afford \\
\hline
\end{tabular}

Synonym highly associated to the cue (set 2)

CUE SYNONYM

ANTONYM

UNRELATED

bold

brave

timid

spacious

curve

bend

straighten

scrub

damage

hurt

repair

hide

damp

wet

dry

wild

debate

argue

agree

obtain 
When "happy" means "sad"

\begin{tabular}{|c|c|c|c|}
\hline decay & rot & thrive & pacify \\
\hline decorate & paint & spoil & combine \\
\hline deficit & loss & excess & frame \\
\hline definite & certain & vague & silent \\
\hline degrade & lower & promote & imagine \\
\hline delay & wait & hurry & aim \\
\hline delicate & fragile & tough & lucky \\
\hline dense & thick & sparse & valid \\
\hline depart & leave & arrive & reflect \\
\hline destiny & fate & chance & generation \\
\hline detect & find & overlook & understand \\
\hline diminish & lessen & grow & hire \\
\hline disease & illness & health & league \\
\hline disgrace & shame & honour & occasion \\
\hline doubtful & dubious & certain & violent \\
\hline dread & fear & welcome & address \\
\hline dreary & dull & cheery & thirsty \\
\hline futile & useless & effective & plain \\
\hline gather & collect & scatter & activate \\
\hline generous & kind & stingy & ready \\
\hline genuine & real & counterfeit & able \\
\hline gradual & slow & abrupt & bold \\
\hline grief & sorrow & joy & appetite \\
\hline harm & hurt & benefit & wonder \\
\hline hasty & quick & deliberate & flat \\
\hline
\end{tabular}


When "happy" means "sad"

$\begin{array}{llll}\text { pick } & \text { choose } & \text { reject } & \text { boost } \\ \text { section } & \text { part } & \text { total } & \text { type } \\ \text { soothe } & \text { calm } & \text { excite } & \text { relate } \\ \text { strange } & \text { odd } & \text { familiar } & \text { willing } \\ \text { victory } & \text { win } & \text { defeat } & \text { page } \\ \text { wary } & \text { careful } & \text { foolhardy } & \text { flexible }\end{array}$

Antonym highly associated to the cue (set 1)

CUE

above

add

adult

after

always

ascend

asleep

buy

clean

cold

come

decrease

empty

enemy

expansion
SYNONYM

over

tally

grown-up

later

invariably

mount

dormant

purchase

spotless

cool

approach

reduce

hollow

rival

enlargement
ANTONYM

below

until

subtract

surround

child

door

before

other

never

along

announce

poisonous

awake

remind

sell

wiry

fair

stock

go

disturb

increase

wild

full

friend

income

contraction

affinity 
When "happy" means "sad"

\begin{tabular}{|c|c|c|c|}
\hline fact & truth & fiction & agony \\
\hline fast & quick & slow & pale \\
\hline float & sail & sink & convince \\
\hline gain & acquire & lose & roar \\
\hline give & offer & take & read \\
\hline happy & cheerful & sad & conscious \\
\hline hate & despise & love & absorb \\
\hline include & comprise & exclude & flick \\
\hline inferior & worse & superior & dramatic \\
\hline live & exist & die & pick \\
\hline more & extra & less & certain \\
\hline near & close & far & still \\
\hline new & modern & old & light \\
\hline pull & drag & push & burn \\
\hline right & correct & wrong & junior \\
\hline rise & climb & fall & stare \\
\hline rough & coarse & smooth & unique \\
\hline soft & fluffy & hard & alternate \\
\hline strong & powerful & weak & central \\
\hline thick & fat & thin & safe \\
\hline under & beneath & over & between \\
\hline
\end{tabular}

Antonym highly associated to the cue (set 2) 
When "happy" means "sad"

\begin{tabular}{|c|c|c|c|}
\hline active & lively & passive & ripe \\
\hline black & murky & white & proud \\
\hline blunt & round & sharp & fair \\
\hline dark & gloomy & light & prompt \\
\hline different & diverse & same & rapid \\
\hline divorce & separation & marriage & fever \\
\hline double & dual & single & blonde \\
\hline down & under & up & still \\
\hline dry & arid & wet & active \\
\hline dull & dingy & bright & medium \\
\hline early & premature & late & absurd \\
\hline first & original & last & local \\
\hline front & beginning & back & ability \\
\hline future & tomorrow & past & wind \\
\hline good & pleasant & bad & late \\
\hline go & advance & stop & realize \\
\hline happy & cheerful & sad & organic \\
\hline heaven & utopia & hell & adjustment \\
\hline heavy & weighty & light & civil \\
\hline long & extended & short & dear \\
\hline loose & slack & tight & serene \\
\hline loser & failure & winner & accent \\
\hline loud & noisy & soft & intact \\
\hline low & deep & high & common \\
\hline major & important & minor & north \\
\hline
\end{tabular}


When "happy" means "sad"

$\begin{array}{llll}\text { majority } & \text { mass } & \text { minority } & \text { advice } \\ \text { many } & \text { abundant } & \text { few } & \text { cubic } \\ \text { masculine } & \text { male } & \text { feminine } & \text { symbolic } \\ \text { minimum } & \text { least } & \text { maximum } & \text { opinion } \\ \text { miss } & \text { ignore } & \text { hit } & \text { jump } \\ \text { sober } & \text { temperate } & \text { drunk } & \text { intricate } \\ \text { sour } & \text { bitter } & \text { sweet } & \text { brief } \\ \text { stand } & \text { rise } & \text { sit } & \text { send } \\ \text { start } & \text { commence } & \text { finish } & \text { appeal } \\ \text { war } & \text { battle } & \text { peace } & \text { season } \\ \text { wide } & \text { expansive } & \text { narrow } & \text { legal }\end{array}$

Test 2

Synonym highly associated to the cue

$\begin{array}{llll}\text { CUE } & \text { SYNONYM } & \text { ASSOCIATE } & \text { UNRELATED } \\ \text { deity } & \text { god } & \text { heaven } & \text { hotel } \\ \text { dirt } & \text { filth } & \text { hand } & \text { guitar } \\ \text { disturbance } & \text { noise } & \text { police } & \text { tissue } \\ \text { document } & \text { paper } & \text { solicitor } & \text { crown } \\ \text { donkey } & \text { ass } & \text { hoof } & \text { diagram } \\ \text { frock } & \text { dress } & \text { party } & \text { pool } \\ \text { gale } & \text { wind } & \text { warning } & \text { throat } \\ \text { gap } & \text { space } & \text { tooth } & \text { cattle } \\ \text { garbage } & \text { rubbish } & \text { bin } & \text { reunion }\end{array}$


When "happy" means "sad"

\begin{tabular}{|c|c|c|c|}
\hline gash & cut & knee & $\sin$ \\
\hline gasp & breath & surprise & grass \\
\hline gaze & look & star & owner \\
\hline gender & sex & female & arm \\
\hline gift & present & ribbon & daylight \\
\hline globe & world & geography & access \\
\hline grab & snatch & smash & reconcile \\
\hline grease & oil & hair & basis \\
\hline hazard & danger & light & quality \\
\hline jail & prison & bar & relationship \\
\hline lid & top & jar & deputy \\
\hline livery & stable & horse & scheme \\
\hline location & place & film & stress \\
\hline loft & attic & house & ratio \\
\hline lotion & cream & face & rhythm \\
\hline madness & insanity & asylum & contour \\
\hline malady & illness & doctor & site \\
\hline martyr & saint & faith & theme \\
\hline material & cloth & wealth & ward \\
\hline midst & middle & crowd & relief \\
\hline mob & crowd & rule & task \\
\hline pile & heap & money & act \\
\hline pistol & gun & bullet & screen \\
\hline price & cost & range & century \\
\hline reply & answer & letter & effort \\
\hline
\end{tabular}


When "happy" means "sad"

$\begin{array}{llll}\text { saliva } & \text { spit } & \text { gland } & \text { agony } \\ \text { tale } & \text { story } & \text { fairy } & \text { source } \\ \text { textile } & \text { cloth } & \text { mill } & \text { horn } \\ \text { toil } & \text { work } & \text { sweat } & \text { walk } \\ \text { tomb } & \text { grave } & \text { stone } & \text { wheel } \\ \text { topic } & \text { subject } & \text { conversation } & \text { village } \\ \text { try } & \text { attempt } & \text { succeed } & \text { translate } \\ \text { twist } & \text { turn } & \text { shout } & \text { vary }\end{array}$

Associate highly associated to the cue

$\begin{array}{llll}\text { CUE } & \text { SYNONYM } & \text { ASSOCIATE } & \text { UNRELATED } \\ \text { crust } & \text { edge } & \text { bread } & \text { nose } \\ \text { damsel } & \text { girl } & \text { distress } & \text { academy } \\ \text { delinquent } & \text { irresponsible } & \text { juvenile } & \text { ironic } \\ \text { den } & \text { burrow } & \text { lion } & \text { recipe } \\ \text { department } & \text { section } & \text { store } & \text { term } \\ \text { desert } & \text { wilderness } & \text { sand } & \text { pip } \\ \text { desk } & \text { table } & \text { chair } & \text { song } \\ \text { diet } & \text { fast } & \text { food } & \text { stage } \\ \text { dive } & \text { plunge } & \text { swim } & \text { forgive } \\ \text { dog } & \text { hound } & \text { cat } & \text { magic } \\ \text { doll } & \text { toy } & \text { house } & \text { grain } \\ \text { donor } & \text { giver } & \text { blood } & \text { branch } \\ \text { dot } & \text { dash } & \text { soul }\end{array}$


When "happy" means "sad"

\begin{tabular}{|c|c|c|c|}
\hline dragon & monster & fly & melody \\
\hline drug & chemical & addict & fuse \\
\hline dumb & mute & deaf & weary \\
\hline fur & hair & coat & pattern \\
\hline garage & storage & car & air \\
\hline generation & era & gap & farmer \\
\hline graft & transplant & skin & factor \\
\hline graph & plot & paper & performance \\
\hline guardian & defender & angel & lung \\
\hline handicap & disability & golf & pearl \\
\hline handle & knob & door & planet \\
\hline harbour & dock & boat & nut \\
\hline headmaster & principal & school & meeting \\
\hline link & connection & chain & wine \\
\hline $\log$ & stick & fire & data \\
\hline lump & cluster & sugar & net \\
\hline matter & substance & fact & text \\
\hline media & publicity & mass & piano \\
\hline medicine & remedy & doctor & unit \\
\hline member & associate & club & concept \\
\hline paint & pigment & brush & jury \\
\hline picture & drawing & frame & tree \\
\hline piece & slice & cake & resident \\
\hline plank & board & wood & sky \\
\hline population & community & explosion & sport \\
\hline
\end{tabular}


When "happy" means "sad"

$\begin{array}{llll}\text { segment } & \text { portion } & \text { orange } & \text { gallery } \\ \text { sentence } & \text { punishment } & \text { death } & \text { nature } \\ \text { swoop } & \text { descent } & \text { bird } & \text { plug } \\ \text { target } & \text { objective } & \text { arrow } & \text { absence }\end{array}$


When "happy" means "sad"

Reference List

Badre, D., Poldrack, R. A., Pare-Blagoev, E. J., Insler, R. Z., \& Wagner, A. D. (2005). Dissociable controlled retrieval and generalized selection mechanisms in ventrolateral prefrontal cortex. Neuron, 47, 907-918.

Bunge, S. A., Wendelken, C., Badre, D., \& Wagner, A. D. (2005). Analogical reasoning and prefrontal cortex: Evidence for separable retrieval and integration mechanisms. Cerebral Cortex, 15, 239-249.

Burgess, P. W. \& Shallice, T. (1997). The Hayling and Brixton Tests. Bury St Edmunds: Thames Valley Test Company.

Cardillo, E. R., Aydelott, J., Matthews, P. M., \& Devlin, J. T. (2004). Left inferior prefrontal cortex activity reflects inhibitory rather than facilitatory priming. Journal of Cognitive Neuroscience, 16, 1552-1561.

Demb, J. B., Desmond, J. E., Wagner, A. D., Vaidya, C. J., Glover, G. H., \& Gabrieli, J. D. E. (1995). Semantic Encoding and Retrieval in the Left Inferior Prefrontal Cortex - A Functional Mri Study of Task-Difficulty and Process Specificity. Journal of Neuroscience, 15, 5870-5878.

Devlin, J. T., Matthews, P. M., \& Rushworth, M. F. S. (2003). Semantic processing in the left inferior prefrontal cortex: A combined functional magnetic resonance imaging and transcranial magnetic stimulation study. Journal of Cognitive Neuroscience, $15,71-84$. 
When "happy" means "sad"

Fletcher, P. C. \& Henson, R. N. A. (2001). Frontal lobes and human memory Insights from functional neuroimaging. Brain, 124, 849-881.

Gold, B. T., Balota, D. A., Kirchhoff, B. A., \& Buckner, R. L. (2005).

Common and dissociable activation patterns associated with controlled semantic and phonological processing: Evidence from fMRI adaptation. Cerebral Cortex, 15, 14381450.

Jung-Beeman, M. (2005). Bilateral brain processes for comprehending natural language. Trends in Cognitive Sciences, 9, 512-518.

Kay, J., Lesser, R., \& Coltheart, M. (1992). Psycholinguistic Assessment of Language Processing in Aphasia. Hove: Psychology Press.

Kiss, G. R., Armstrong, C., Milroy, R., \& Piper, J. (1973). An associative thesaurus of English and its computer analysis. In A.J.Aitken, R. W. Bailey, \& N. Hamilton-Smith (Eds.), The computer and literary studies ( Edinburgh: University Press.

McKenna, P. (1997). Category-Specific Names Test. East Sussex: Psychology Press.

Metzler, C. (2001). Effects of left frontal lesions on the selection of contextappropriate meanings. Neuropsychology, 15, 315-328.

Moss, H. E., Abdallah, S., Fletcher, P., Bright, P., Pilgrim, L., Acres, K. et al. (2005). Selecting among competing alternatives: Selection and retrieval in the left inferior frontal gyrus. Cerebral Cortex, 15, 1723-1735. 
When "happy" means "sad"

Reitan, R. M. (1958). Validity of the trail making test as an indicator of organic brain damage. Perceptual and Motor Skills, 8, 271-276.

Robertson, I. H., Ward, T., Ridgeway, V., \& Nimmo-Smith, I. (1994). The test of everyday attention. Cambridge: The Thames Valley Test Company.

Roskies, A. L., Fiez, J. A., Balota, D. A., Raichle, M. E., \& Petersen, S. E. (2001). Task-dependent modulation of regions in the left inferior frontal cortex during semantic processing. Journal of Cognitive Neuroscience, 13, 829-843.

Sharp, D. J., Scott, S. K., \& Wise, R. J. S. (2004). Monitoring and the controlled processing of meaning: Distinct prefrontal systems. Cerebral Cortex, 14, 110.

Thiel, A., Haupt, W. F., Habedank, B., Winhuisen, L., Herholz, K., Kessler, J. et al. (2005). Neuroimaging-guided rTMS of the left inferior frontal gyrus interferes with repetition priming. Neuroimage, 25, 815-823.

Thompson-Schill, S. L., D'Esposito, M., Aguirre, G. K., \& Farah, M. J. (1997). Role of left inferior prefrontal cortex in retrieval of semantic knowledge: A reevaluation. Proceedings of the National Academy of Sciences of the United States of America, 94, 14792-14797.

Thompson-Schill, S. L., D'Esposito, M., \& Kan, I. P. (1999). Effects of repetition and competition on activity in left prefrontal cortex during word generation. Neuron, 23, 513-522.

Thompson-Schill, S. L., Swick, D., Farah, M. J., D'Esposito, M., Kan, I. P., \& Knight, R. T. (1998). Verb generation in patients with focal frontal lesions: A 
When "happy" means "sad"

neuropsychological test of neuroimaging findings. Proceedings of the National Academy of Sciences of the United States of America, 95, 15855-15860.

Wagner, A. D., Koutstaal, W., Maril, A., Schacter, D. L., \& Buckner, R. L. (2000). Task-specific repetition priming in left inferior prefrontal cortex. Cerebral Cortex, 10, 1176-1184.

Wagner, A. D., Pare-Blagoev, E. J., Clark, J., \& Poldrack, R. A. (2001). Recovering meaning: Left prefrontal cortex guides controlled semantic retrieval. Neuron, 31, 329-338.

Zhang, J. X., Feng, C. M., Fox, P. T., Gao, J. H., \& Tan, L. H. (2004). Is left inferior frontal gyrus a general mechanism for selection? Neuroimage, 23, 596-603. 


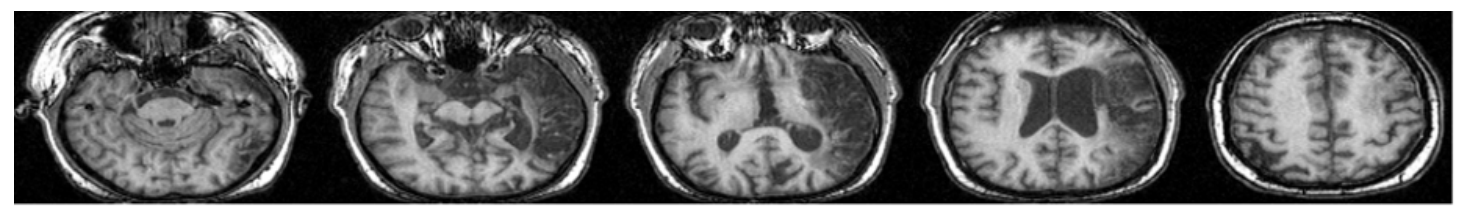

Figure 1. MRI scans (T1-weighted axial slices) showing PW's right fronto-temporal lesion.

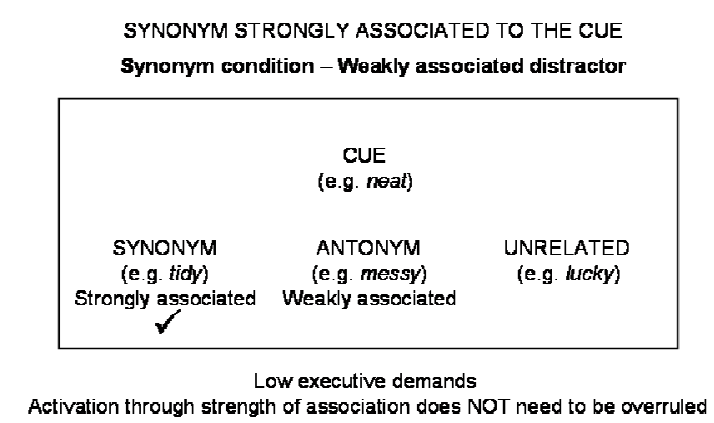

Antonym condition - Strongly associated distractor

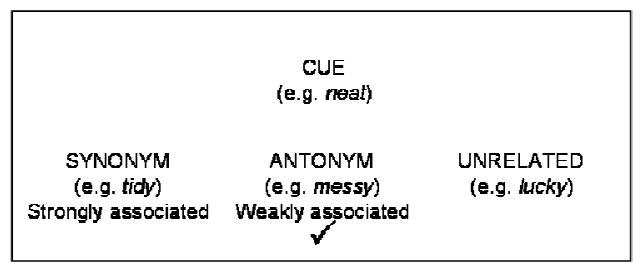

High executive demands

Activation through strength of association needs to be overruled
ANTONYM STRONGLY ASSOCIATED TO THE CUE Symonym condition - Strongly associated distractor

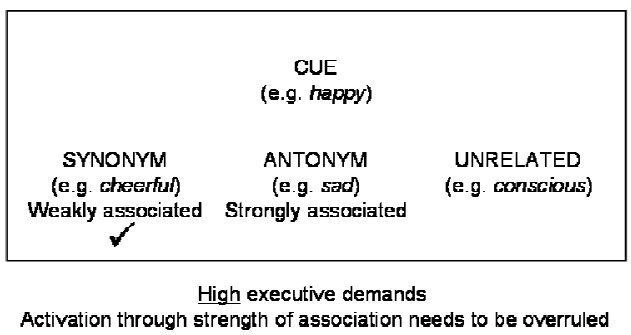

Antonym condition - Weakly associated distractor

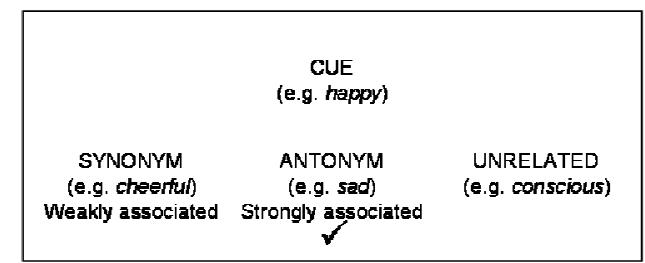

Low executive demands

Activation through strength of association does NOT need to be overruled

Figure 2. Executive demands in Experiment 1 as a function of the strength of association of the distractor. The ticks indicate the correct response in each experimental condition. 
When "happy" means "sad"

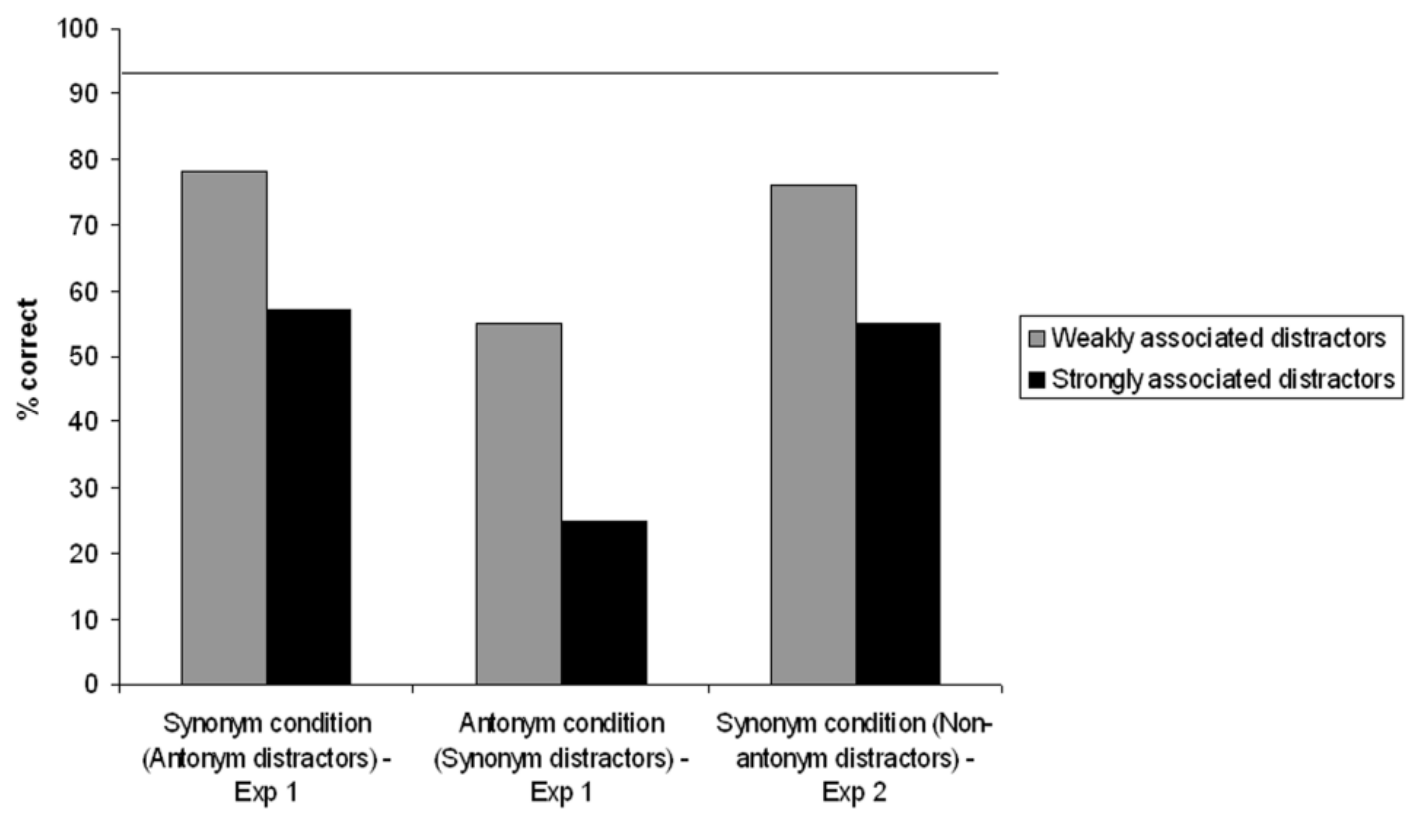

Figure 3. PW's percentage correct responses in Experiments 1 and 2 according to the strength of association between the cue and the distractor. The line at $93 \%$ shows the lowest performance of the control participants. 